RESEARCH ARTICLE

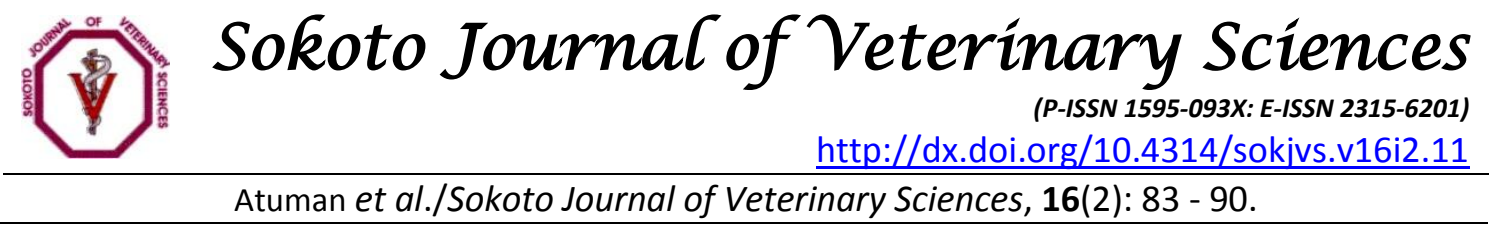

\title{
Seroprevalence of bovine tuberculosis and brucellosis in Agropastoralist livestock herds and wildlife in Yankari game reserve: Public health implications
}

\author{
JY Atuman ${ }^{1}$, S Ibrahim ${ }^{2} *$ Al Abubakar ${ }^{3} \&$ CA Kudi $^{2}$ \\ 1. National Veterinary Research Institute zonal office Bauchi, Bauchi State, Nigeria \\ 2. Department of Veterinary Medicine, Faculty of Veterinary Medicine, Ahmadu Bello University Zaria, Nigeria \\ 3. Nigeria Police Force, K9 Section, Jos, Plateau State, Nigeria
}

*Correspondence: Tel.: +2348032871906; E-mail: sihadejia@gmail.com

\begin{abstract}
Copyright: (C) 2018
Atuman et al. This is an open-access article published under the terms of the Creative Commons Attribution License which permits unrestricted use, distribution, and reproduction in any medium, provided the original author and source are credited.
\end{abstract}

Publication History:

Received: 12-09- 2017

Accepted: 05-03-2017

\begin{abstract}
Wildlife, livestock, people and particularly communities surrounding Yankari Game Reserve of Bauchi State, Nigeria compete for spaces and available resources. This study was therefore designed to determine the seroprevalence of bovine tuberculosis (bTB) and brucellosis which are zoonotic. Serum samples were collected from 300 cattle located at the fringes of the game parks and also from 47 zebra, 12 waterbuck, 12 wildebeest, 24 eland, 1 kudu and 1 hartebeest during the study. The samples were tested for the presence of immunoglobulin antibodies against Mycobacterium bovis, Brucella abortus and B. melitensis using immunochromatography rapid test kits (Bionote Incorporated, South Korea).The percentage of positive bTB reactors were $30(10 \%)$ in cattle $5(10.6 \%)$ zebra, $1(8.3 \%)$ waterbuck, $4(33.3 \%)$ wildebeest and $3(12.5 \%)$ Eland. The sex distribution of bTB among cattle showed that of the 104 males sampled 12(11.5\%) were positive and of the 196 females sampled 18(9.2\%) were positive. The sex distribution of bTB among the diversity of wildlife species sampled indicated higher prevalence in female zebra $18.8 \%$, waterbuck $14.3 \%$ and eland $16.7 \%$ compared to male zebra $6.5 \%$, waterbuck $0 \%$, and eland $8.3 \%$. Positive reactors to $\mathrm{B}$. abortus were seen in cattle $27(9 \%)$, hartebeest $1(100 \%)$, eland $4(16.7 \%)$, waterbuck $3(25 \%)$ and eland $4(16.7 \%)$. Sex distribution of B. abortus and B. melitensis among cattle showed that of the 104 males sampled, 10(9.6\%) cattle were positive for B. abortus and the 196 females sampled $17(8.7 \%)$ were positive for B. abortus. The high prevalence of B. abortus in male Eland $(25 \%)$ and waterbuck $(40 \%)$ portends danger to the herds. The presence of antibodies of bTB and B.abortus in both cattle and wildlife species and B. melitensis in wildlife species showed that the diseases are likely to pose significant threat to public health. There is the need for enlightenment of the herders and communities of the dangers of these important diseases.
\end{abstract}

Keywords: Bauchi state, Bovine, Brucellosis, Cattle, Tuberculosis, Wildlife

\section{Introduction}

Bovine tuberculosis (bTB) caused by Mycobacterium bovis ( $M$. bovis) is a chronic, infectious and contagious disease of livestock, wildlife and humans
(O Reilly \& Daborn, 1995). The disease is an important public health concern worldwide, especially in developing countries, due to 
deficiencies in preventive and/or control measures (Etter et al., 2006). The incidence of $M$. bovis in humans probably remains underestimated, as distinction between $M$. bovis and M.tuberculosis, is not systematically performed (Etter et al., 2006). Since the real incidence of $M$. bovis on human health is still unknown, it is essential to advance the eradication of bTB worldwide by means of adequate programmes, especially in developing countries (Grange, 2001). Members of the closely related phylogenic grouping of Mycobacterium known collectively as the Mycobacterium tuberculosis complex may cause tuberculosis in a range of species including man. Some members of this group are predominately human ( $M$. tuberculosis, $M$. africanum, $M$. canetti) or rodent pathogens ( $M$. microti), whereas, others have wide host spectrum (M. bovis, M.caprae) (Brosch et al., 2002). The respiratory route is accepted as the primary method of infection spread in all species. However, it is clear that there are other less common methods of spread such as oral, occupational, congenital and via wounds (Thoen et al., 2006; Doran et al., 2009).

Brucellosis primarily affects cattle, pigs, sheep, goats and occasionally horses. In wildlife, the prevalence could be low but there is always a clear epidemiological link between wildlife and domestic animals (Godfroid et al., 2005). Brucella species was first described as far back 1887 as Micrococcus melitensis in Malta in a British soldier who died of the disease. The causative organism was later renamed Brucella melitensis. Brucella melitensis has been rated by WHO as one of the most important zoonoses, as it is very pathogenic to humans, causing the disease known as Malta fever (also known as Mediterranean or undulating fever) (Pappas et al., 2006). The increased awareness of the existence of the different Brucella species in many different regions in the world may be due to the contribution of the increased ability of the organism to be transmitted, rapidly and efficiently, over vast distances in modern day society and an increased awareness of the socio-economic impact of infection in both human and different animal species (Maxwell \& Bill, 2008).

Wildlife diseases are increasingly important in wildlife conservation, particularly when endangered species or human health are involved (Daszak et al., 2000). The world is undergoing rapid ecological change, populated by pathogenic organisms, their vectors and hosts which are capable of equally rapid change (Williams et al., 2002). Some of these pathogens may cause significant disease in wild species, but in other cases the wild animals may serve as reservoirs for pathogens which do not induce overt illness in their wild hosts (Williams et al., 2002). Three-quarters of all emerging infectious diseases of humans are zoonotic, most of which are of wildlife origin, with an increasing incidence since the 1940s (Taylor et al., 2001; Jones et al., 2008). Diseases transmitted from domestic livestock populations into wild animal populations can have several deleterious effects. Once disease is established in a wild population, control measures in domestic populations or free ranging livestock become much problematic. It has been shown that an infected wildlife reservoir that interacts with livestock causes frequent herd breakdown and substantial economic losses to agricultural sector (McDermott \& Arimi, 2002).

Precise data on the sero-prevalence in wildlife is difficult to obtain for most regions of the world, like Nigeria. Many studies and results of surveys, or other official records, have been published or may be available, but to what extent this may truly reflect the prevalence is unknown in the wildlife (WHO/MZCP, 1998). The objective of this study was to determine the presence of $M$. bovis and brucella infections in wildlife in Yankari Game Reserve and also to determine the prevalence $M$. bovis and brucella infection in cattle settlements around Yankari Game Reserve.

\section{Materials and Methods \\ Study area}

The Yankari game reserve is one of the largest wildlife parks located in the South-central part of Bauchi State in the North-east zone of Nigeria. It lies between latitude 9.75000 North and longitude 10.500005 West. It covers an area of about $2.244 \mathrm{~km}^{2}$ and is home to several natural springs, as well as to a wide variety of flora and fauna. The game reserve is situated in the heartland of West African savanna and has characteristic savanna vegetation, including swamps with river floodplains, grassland and thick bushes (Odunlami, 2000). It is the most popular tourist destination in Nigeria, which is rich in wildlife, including baboons, crocodiles, elephants, giraffes, hippopotamuses, hyenas, leopards, lions, and several species of antelopes. It is also one of the most popular ecodestinations in West Africa (Olekesusi, 1990). The park features four warm water springs and one cool water spring. Annual rainfall in the Yankari Game Reserve is between $900 \mathrm{~mm}$ and $1,000 \mathrm{~mm}$. The rainy season is from May to September. 
Temperatures range between $18^{\circ} \mathrm{C}$ and $35^{\circ} \mathrm{C}$ (Marguba, 2000). During dry season, the larger wildlife species in the Yankari Game Reserve depend on the Gaji River and its tributaries for their water needs (Marguba, 2000).

\section{Sample size determination}

Convenience sampling and purposive sampling were used to select cattle and wildlife species respectively. A total of 397 samples were collected, consisting of 300 cattle and 97 wild animals.

\section{Sampling procedure}

Convenience sampling was used to identify the herds to be sampled. Any herd with 10 cattle and above living around the Yankari Game Reserve was identified and from each herd blood samples were collected from cattle over 6 months of age. As for the wildlife species, identified animals were darted using etorphine hydrochloride in order to have access to animals in order to collect blood samples. Sick wildlife under treatment by the resident Veterinarian and captured wildlife staff and hunters were also used to obtain the samples.

\section{Blood collection from cattle}

The ages, sexes, and breeds of cattle that were sampled were recorded. The age was determined by the use of permanent incisors teeth as described by Pace \& Wakeman (2003). The different breeds were determined by the use of body characteristics as described by Mason (1996), Tawah \& Rege (1996) and Rege \& Tawah (1999) for Red Bororo, Sokoto Gudali and White Fulani respectively. Sexes were also determined as described by Tawah \& Rege (1996). Each animal was physically restrained and $5 \mathrm{mls}$ of jugular blood were obtained using a sterile disposables $10 \mathrm{mls}$ syringe to which an $18 \mathrm{G}$ needle was attached. The syringe was kept in a slanting position to allow the serum to separate from the blood; the serum was carefully dispensed into a $20 \mathrm{ml}$ sterile sample bottle and appropriately labelled. A total of 300 cattle were sampled. The samples were stored at $-20^{\circ} \mathrm{C}$ at National Veterinary Research Institute State Laboratry in Bauchi. The samples were then transported over ice to Protozoology Laboratory Department of Veterinary Parasitology and Entomology, Ahmadu Bello University Zaria, where they were stored at $-20^{\circ} \mathrm{C}$ until used.

Blood collection from wildlife species
Blood samples were obtained from different wild animals associated with the Yankari Game Reserve. A total of 97 animals were sampled. Healthy and sick wildlife species located in the Reserve as well as wild animals captured by hunters were sampled. Wild animals were chemically restrained using etorphine via dart gun administered by wildlife staff. Blood samples were then taken from the wildlife through the jugular vein and tarsal vein by the resident veterinarian during the sedation period. Serum samples were then separated from each sampled blood, appropriately labelled and stored at $-20^{\circ} \mathrm{C}$ until used.

\section{Sources of test kits}

The rapid, immunochromatography bTB Antibodies (RbTBAb) test kit (Bionote Incorporated, Seogudong, Hwaseong-si, Gyeonggi-do, South Korea), was used for the detection of $M$. bovis antibodies in the serum samples from sampled cattle and wildlife species. The RbTBAb test kit is based on a chromatographic immunoassay for the quantitative detection of IgG and IgM antibodies against $M$. bovis in serum, plasma or whole blood. The MPB70 is a specie-specific protein produced by $M$. bovis and is a major antigen from culture filtrate protein of $M$. bovis. It has a sensitivity of $90 \%$ and a specificity of 98\% (Wikers, 2009). The test kit for Brucella was from the same manufacturer with that of $M$. bovis.

\section{Laboratory analysis}

Serum analyses for $M$. bovis, B.abortus and B.melitensis

Each test kit has a sample hole and developing buffer hole. The serological test was carried out according to the manufacturer's instructions. The result was interpreted within 20 minutes, any result obtained after 20 minutes was considered as invalid.

\section{Data analysis}

Data obtained were expressed as percentages in tables and graphs where necessary. Chi-square test was used to test for the association between the presence of antibodies and the age, sex, breed of cattle and wildlife type. Graph-pad prism Version 4.0 for windows (SanDiego California, USA) was used for the data analysis, while the level of significance at 95\% confidence interval and $\mathrm{P} \leq 0.005$ was considered significant.

\section{Results}


The results of the prevalence of bovine tuberculosis and brucellosis in wildlife and cattle in and around Yankari Game Reserve (YGR) are shown in Table 1. Amongst the 397 wildlife and cattle sampled and tested for bovine tuberculosis (bTb), the Wildebeest (32.3\%) had the highest percentage prevalence followed by Eland (12.5\%), Zebra (10.6\%) and cattle (10\%). Both Kudu and Hartebeest tested negative for Btb. On the other hand, for Brucella abortus infection in wildlife, the Hartebeest (100\%), Waterbuck (25\%) and Eland (16.7\%) were positive while cattle gave a prevalence of $9 \%$. Results for $B$. melitensis infection recorded a prevalence of: Wildebeest (25\%), Eland (12.5\%) and Waterbuck (8.3\%) - Table 1. Based on sex distribution, it was observed that, kudu was the only female sampled and was positive(100\%), Wildebeest (40\%), Zebra (18.8\%), Waterbuck (14.3\%) and Eland(16.7\%) for wildlife while female cattle had a prevalence of $9.3 \%$. While in males only the Hartebeest (100\%) and Wildebeest $42 \%$ were positive for bTB (Table 2). Similar results were obtained for both $B$. abortus and $B$. melitensis with females having higher prevalence than males (Table 2). Animal species having higher prevalence for both B.abortus and B.melitensis were Waterbuck and Eland $(25 \%$ and $8.3 \%$ and $12.5 \%$ respectively) (Table 1). However there was no case of mixed infection in this study $(0 \%)$. The results obtained for both B. abortus and B. melitensis had female zebras and wildebeest having higher prevalence than males whereas male Elands waterbuck and cattle males had higher prevalence than females (Table 3).

\section{Discussion}

The finding of bTB and brucellosis antibodies in wildlife and cattle is of significance especially when the epidemiology of these 2 diseases is taken into consideration as they both affect the livestock productivity and are also zoonotic, thus of public health importance. The proximity of cattle-grazing to wildlife population makes interspecies disease transmission a concern (Godfroid, 2002). The zoonotic implication is of importance as the game reserve is used for both ecotourism and grazing of livestock. It is suggested by some workers that, interaction between wildlife environment and livestock could be a source of infection to the livestock which may in turn be a source to other susceptible livestock not in the vicinity of the game reserve. This statement is supported by the fact that of many workers who stated that many important diseases of livestock are shared among species, including rift valley fever, brucellosis and tuberculosis (Daszak et al., 2000, Tomley \& Shirley, 2009). Game viewing, swimming and other recreational activities like camping in the reserve

Table 1: Prevalence of bTB and Brucella infections in Wildlife and Cattle in YGR

\begin{tabular}{lllcc}
\hline Species & Total Sampled & \multicolumn{3}{c}{ Number (and percent) positive infection for: } \\
\cline { 3 - 5 } & & Btb & B. abortus & B. melitensis \\
\hline Zebra & 47 & $5(10.6)$ & $7(14.9)$ & $0(0)$ \\
Waterbuck & 12 & $1(8.3)$ & $3(25)$ & $1(8.3)$ \\
Wildebeest & 12 & $4(33.3)$ & $0(0)$ & $3(25)$ \\
Eland & 24 & $3(12.5)$ & $4(16.7)$ & $3(12.5)$ \\
Kudu & 1 & $0(0)$ & $0(0)$ & $0(0)$ \\
Hartebeest & 1 & $0(0)$ & $1(100)$ & $0(0)$ \\
Cattle & 300 & $30(10)$ & $27(9)$ & $0(0)$ \\
\hline
\end{tabular}

Table 2: Prevalence of bTB based on Sex of Wildlife Species and Cattle in YGR

\begin{tabular}{lllllll}
\hline Species & \multicolumn{2}{c}{ Male } & & \multicolumn{2}{c}{ Female } \\
\hline & Total sampled & $\begin{array}{l}\text { Number } \\
\text { Positive }\end{array}$ & $\begin{array}{l}\text { Percentage } \\
\text { Positive }\end{array}$ & $\begin{array}{l}\text { Total } \\
\text { Sampled }\end{array}$ & $\begin{array}{l}\text { Number positive } \\
\text { Percentage } \\
\text { Positive }\end{array}$ \\
\hline Zebra & 31 & 2 & 6.5 & 16 & 3 & 18.8 \\
Waterbuck & 5 & 0 & 0.0 & 7 & 1 & 14.3 \\
Widebeest & 7 & 3 & 42.9 & 5 & 1 & 20.0 \\
Eland & 12 & 1 & 8.3 & 12 & 2 & 16.7 \\
Kudu & 0 & 0 & 100 & 0 & 1 & 0.0 \\
Hartebeest & 1 & 1 & 11.5 & 196 & 18 & 9.2 \\
Cattle & 104 & 12 & & & 0 & 18 \\
\hline
\end{tabular}


Table 3: Prevalence of B. abortus and B. melitensis in Males and Females in wildlife and cattle in YGR

\begin{tabular}{lllll}
\hline & Species & $\begin{array}{l}\text { Number } \\
\text { sampled }\end{array}$ & $\begin{array}{l}\text { B. abortus } \\
\text { +ve(\%) }\end{array}$ & $\begin{array}{l}\text { B. melitensis } \\
\text { +ve (\%) }\end{array}$ \\
\hline Male & Zebra & 31 & $3(9.7)$ & $0(0)$ \\
& Waterbuck & 5 & $2(40)$ & $0(0)$ \\
& Wildebeest & 7 & $0(0)$ & $0(0)$ \\
& Eland & 12 & $3(25)$ & $2(16.7)$ \\
& Kudu & 0 & 0 & $0(0)$ \\
& Hartebeast & 1 & $0(0)$ & $0(0)$ \\
& Cattle & 104 & $10(9.6)$ & $0(0)$ \\
\hline Female & Zebra & 16 & $4(25)$ & $0(0)$ \\
& Water buck & 7 & $1(4.3)$ & $0(0)$ \\
& Wildebeest & 5 & $0(0)$ & $3(60)$ \\
& Elenad & 12 & $1(8.3)$ & $0(0)$ \\
& Kudu & 1 & $1(100)$ & $0(0)$ \\
& Hartebeast & 1 & $0(0)$ & $0(0)$ \\
& Cattle & 196 & $17(8.7)$ & $0(0)$ \\
\hline
\end{tabular}

also may be a source of infection to humans as humans often used the same environment used especially by wild ungulates. These activities and other factors have been reported to be potential ways and sources for human infection by these 2 diseases (Pappas et al., 2006). Bovine tuberculosis in roan antelope is not surprising as there had been evidence of exposure in similar species such as antelope in other countries (De Lisle et al., 2002; Nishi et al., 2005). However, because indication of infection has been found in this study, shows that this could play a significant role in transmission between cattle and wildlife especially as cattle play a significant role in transmission between cattle and wildlife especially as cattle herders often encroach into the grazing reserve in search of pasture. These pastures are often grazed by antelopes and other wildlife. Sharing these environments could play a role in transmission. Also, the activity of poachers and slaughter of cattle for meat could contribute in the spread of infection with these diseases among animals and humans far away from the game reserve from infected tissues and contamination of the environment. It was reported by Mfinanga et al. (2003) that pastoralists and agro-pastoralists are considered high risk groups for contracting bTB and brucellosis due to their close association with livestock and diets rich in animal products. Both diseases have been reported in many wildlife, livestock and human interface in Africa (Munyeme \& Muanangandu, 2011; Gomo et al., 2012; Jori et al., 2013; Katale et al., 2013).

Humans have been known to contract bTB infections through inhalation and consumption of infected undercooked meat or game or unpasteurized cattle milk, hence, with this findings, humans are at risk of being infected especially those around the YGR. Bovine tuberculosis's main route of infection is through aerosol, so people engaging in tourism and ecotourism to the YGR are also at risk. This is more so because of the human population growth and associated changes, as well as competition for grazing lands, have made wildlife-livestock disease transmission more likely by reducing the spatial separation between livestock operations and wildlife habitat (Daszak et al., 2001). Humans are known to contact the disease through contact with infected meat and tissues during slaughter operations, interaction with infected environment and handling infected animal products without adequate protection (Young \& Suvannoparrat, 1975).

The trend of female wildlife and cattle reacting more positive than their male counterpart have been reported for domestic animals and also indicated in this study for cattle (Justin et al., 2015). Similar finding is seen in this study for wildlife however this could not be ascertained because the number of animals used was very low due to the ethics of capturing and releasing these wild animals. It is however very important finding and only a wider study, involving large number of wildlife species could confirm infections based on sex.

Zebra is the only species of wildlife in this study, that is not a ruminant, yet having tested positive. The finding in zebra could indicate a more widespread infection of wildlife in YGR as bTB is a disease of all warm blooded animals.

This is the first time antibodies to Brucella species is being reported in wildlife in Nigeria to the best of our knowledge. Even though this is not surprising as 
the disease is endemic in Nigeria. The only possible explanation is that it could be through grazing of ruminants and other animals and interacting in the same environment with wildlife. Studies have found that both mixing with other herds and increasing herd size was associated with higher seroprevalence of these diseases (Matope et al., 2010; McDermott \& Arimi, 2002). This confirms the findings in this study as the grazing reserve serves as a meeting point for many herds in search of grazing areas and water which is abundant in the Game reserve. It was only in the roan antelope family that B.melitensis positive animals were detected. This because small ruminants are the normal hosts of $B$ melitensis and similar phenotypic and genetic characteristics may play a part.

Management of these diseases at the wildlifelivestock interface is hampered by the challenge of balancing wildlife conservation with livelihood and traditions of livestock producers. Some hosts may be persistent reserviours of disease and others may be recurrently infected through pathogen spillover (Power \& Mitchell, 2004). Hence overall diseases with multiple wildlife and livestock hosts, as the case may with these 2 diseases, are deemed extremely difficult to control and eradicate (Delahay et al., 2009). Therefore, the potential for transmission between wildlife exacerbates conflict between national resources managers and cattlemen reduces tolerance for wildlife near livestock operations, and negatively impacts conservation. Hence, diseases that affect both wildlife and livestock are important in resource management regardless of their direct impact to the wild animal population, which may serve as their reservoirs.

The manifestation of these 2 diseases in cattle and wildlife in the game reserve could indicate that they may be endemic as there are continuous interactions between cattle-wildlife-humans. Study by (Odunlami, 2000) have shown that once an animal is infected, there is little evidence to suggest that it will ever recover from infection, and it is recommended that it be considered a carrier for life, even if no abortions or other signs occur. This multireservoir system poses significant challenges to comprehensive disease management especially its effect on public health (Delahay et al., 2009). There is the need for enlightenment of the herders and communities at the fringes of the game reserve of the dangers of these important diseases. Targeted surveillance for important zoonotic diseases like Tuberculosis and Brucellosis among wildlife species in Nigeria is advocated.

\section{References}

Brosch R, Gordon SV \& Marmiesse M (2002). A new evolutionary scenario for the mycobacterium tuberculosis complex. Proceedings of the National Academy of Science of the United State of America, 99 (6): $3684-3689$.

Daborn CJ, Grange JM \& Kazwala RR (2009). The bovine tuberculosis cycle: An African perspective. Journal of Applied Bacteriology, 81(s25): $275-325$.

Daszak P, Cunningham AA, \& Hyatt, AD (2000). Emerging infectious diseases of wildlife Threats to biodiversity and human health. Science Journal, 287(5452): 443 - 449.

Daszak P, Cunningham AA \& Hyatt AD (2001). Anthropogenic enviromental change and the emergence of infectious disease in wildlife. Acta Tropica, 78(2): 103-116.

Delahay RJG, Smith GC, Barlow AM Walker N, Harris A, Clifton-Hadley RS \& Cheeseman CL (2009). Bovine tuberculosis infection in wild mammals in the South-west region of England:Survey of prevalence and semiquantitative assessment of relative risk to cattle. Veterinary Journal, 173(2): 287-301.

De Lisle G, Bengis R, Schemitt S \& O'Brien D (2002). Tuberculosis in free-ranging wildlife: detection, diagnosis and management. Review of Scientific and technical office of International epizootic. 21(1): 317 - 33.

Doran P, Carson J, Castello E \& More SJ (2009). An outbreak of tuberculosis affecting cattle and people on an Irish dairy farm,following the consumption of raw milk. Irish Veterinary Journal, 62(6): 390-397.

Etter E, Donado P, Jori F, Caron A, Goutard F \& Roger F (2006). Risk analysis and bovine tuberculosis, a re-emerging zoonosis. Annals of New York Academy of Science, 108(1): 112.

Godfroid J (2002). Brucellosis in wildlife. Revue Scientifique et Technique-Office international des épizooties, 21 (1): 277286.

Godfroid J, Clocakacrt A \& Liqutard JP (2005). From the discovery of the Malta fever's agent to the discovery of a marine reservoiur, brucellosis has been continuous reemerging zoonoses. Veterinary Research, doi: 10.1051/vetres:2005003. 
Gomo C, Musari S, De Garine-Wichattsky M, Caron A, Pfukenyi DM \& Van Heerden H (2012). Detection of Brucella abortus in Chiredzi district Zimbabwe. Onderstepoort Journal of Veterinary Research, 79(1):417-422.

Grange JM (2001). Mycobacterium bovis infection in human beings. Tuberculosis, 81(1-2): 71 -77.

Jones KE, Patel NG, Levym MA, Storeygard A, Balk D, Gittleman, JL \& Daszak P (2008). Global trend in emerging infectious diseases. Nature, 451(7181): 990 - 993.

Jori F, Brahmbhatt D, Fosgate GT, Thompson PN, Budke C, Word MP, Ferguson K \& Gummow B (2013). A questionaire-based evaluation of veterinary cordon fence separating wildlife and livestock along the boundry of kruger national park, South Africa. Preventive Veterinary Medicine, 100(3-4): 210-220.

Justin AA, Lucas EM, Shabani KM, Joseph M \& Rudovick RK (2015). Epidemiology of Brucella infection in the human, livestock and wildlife interface in the Katavi-Rukwa ecosystem, Tanzania. BMC Veterinary Research, 11(1): 189.

Katale BZ, Mbugi EV, Karimuribo ED, Keyyu JD, Kendall S, Kibiki GS, Godfrey-Faussett $P$, Michel AL, Kazwala RR, Van Helden P \& Matee MI (2013). Prevalence and riskfactors for infection of bovine tuberculosis in indigenous cattle in the serengeti ecosystem, Tanzania. BMC Veterinary Research, 9(1):267.

Marguba LB (2000). National Parks and their Benefits to Local Communities in Nigeria. A paper presented at the fourth International Ecotourism Symposium of Africa Travel Association at Sheraton Hotel, Abuja, Nigeria.

Mason IL (1996). A World Dictionary of Livestock Breeds, Types and Varieties. Fourth Edition. CAB International. Wallingford, UK. Pp 273.

Matope G, Bhebhe E, Muma JB, Lund A \& Skejerve E (2010). Herd-level factors for Brucella seropositivity in cattle reared in smallholder dairy farms of Zimbabwe. Preventive Veterinary Medicine, 94(3-4): 213-221.

Maxwell JR \& Bill DE (2008). Developing a brucellosis public health information and awareness campaign in Iraq. Military Medicine, 17(1): $79-84$

McDermott JJ \& Arimi SM (2002). Brucellosis in SubSaharan Africa: Epidemiology, control and impact. Veterinary Microbiology, 90(1-4: $111-134$.

Mfinanga SG, Morkre O,Kazwala RR (2003).The role of livestock keeping in tuberculosis trend in Arusha, Tanzania. International Journal of Tuberculosis and Lung Disease, 7(7): 695704.

Munyeme M \& Muanangandu (2011). A review of bovine tuberculosis in the Kafue basin ecosystem. Veterinary Medicine International, doi:10.4061/2011/918743.

Nishi JS, Shury T \& Elkin BT (2006). Wildlife reservoirs for bovine tuberculosis (Mycobacterium bovis) in Canada: strategies for management and research. Veterinary Microbiology, 112(2-4): 325-338.

Olekesusi F (1990). Assessment of the Yankari Game Reserve, Nigeria: Problems and Prospects. Butterworth Heineman Limited, London, UK. Pp 153-155.

O'Reilly LM \& Daborn CJ (1995). The epidemiology of $M$. bovis infections in animals and man: A review. Tubercle and Lung Diseases, 76 (Supplement 1): $1-46$.

Odunlami SSS (2000). "Parks": Vanguard of Ecotourism Promotion. The Host Magazine. 2 (1): 25-31.

Pace JF \& Wakeman DL (2003). Determining the age of cattle by their teeth. University of Florida Cooperative Extension Service, Institute of Food and Agriculture Sciences, https://www.extension.umn.edu/youth/mn 4-H/projects/docs/Beef-Mouthing-InfoSheet.pdf, retrieved 12-08-2017.

Pappas G, Papadimitriou P, Akritidis N, Christou L \& Tsianos EV (2006). The new global map of human brucellosis. Lancet Infectious Diseases, 6(2): 91 - 99.

Power AG \& Mitchell CE (2004). Pathogen spillover in disease epidemics. The American Naturalist, 164(S5): 79-89.

Rege JEO \& Tawah CL (1999). The state of African cattle genetic resources II. Geographical distribution, characteristics and uses of present day breeds and strains. FAO/UNEP Animal Genetic Resources Information Bulletin.

http://agtr.ilri.cgiar.org/agtrweb/Document s/Library/docs/agri26_99.pdf\#page=7, retrieved 11-08-2017.

Tawah CL \& Rege JEO (1996). Gudali Cattle of West and Central Africa. FAO Animal Genetics Resources Information Bulletin. 17: 147-164. 
Taylor LH, Latham SM \& Woolhouse MEJ (2001). Risk factors for human disease emergence. Philosophical Transaction of the Royal Society B: Biological Sciences, 356(1411): 983-989.

Thoen C, Lobue P \& Dekantor I (2006). The importance of $M$. bovis as a zoonosis. Veterinary Microbiology, $112(2-4)$ : $339-$ 345.

Tomley FM \& Shirley MW (2009).Livestock infectious diseases and zoonoses. Philosophical Transactions of the Royal Society $B$, 364(1530): 2637-2642.

WHO/MZCP (1998). Human and Animal Brucellosis Report of a WHO/MSCP Workshop,
Damascus, Syrian Arab Republic. 1998. http://www.mzcpzoonoses.gr/pdfen/Brucel losis.pdf,2007, retrieved 11-06-2007.

Wiker HK (2009). MPB70 and MPB80 Major antigens of Mycobacterium bovis. Scandinavian Journal of Immunology, 69(6): 492 - 499.

Williams ES, Yuli T, Artois M, Fischer J \& Huigh SA (2002). Emerging infectious diseases in wildlife. Review of Scientific and technical officeof Inernational Epizootic. 21(1): 139 157.

Young EJ \& Suvannoparrat U (1975). Brucellosis outbreak attributed to ingestion of unpasteurized goat cheese. Archives of Internal Medicine, 135(2): 240-243. 